\title{
Trend of Intravitreal Bevacizumab Dispensing Technique in Nepal
}

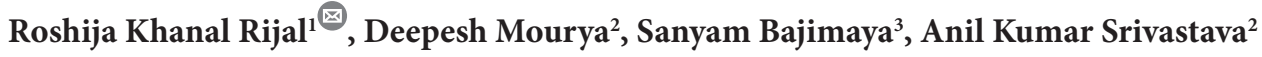 \\ ${ }^{1}$ ASG Eye Hospital, Kathmandu, Nepal \\ ${ }^{2}$ Raj Eye Hospital, Gorakhpur, India \\ ${ }^{3}$ Tilganga Institute of Ophthalmology
}

\begin{abstract}
Introduction: The main purpose of this survey was to find out what technique for bevacizumab injection is practiced by ophthalmologists in Nepal and to evaluate which is the best technique of drug dispensing and what possible hindrances are there in following it.

Materials and methods: This was an online survey using google forms.

Results: There were a total of 34 participants in the survey. Most of the participants (58.8\%) followed the same vial, multiple prick, multiple days method for giving intravitreal bevacizumab.. Majority of participants said they thought that aliquoting the drug and using it same day would be the best technique to prevent post injection endophthalmitis. Cost and unsuitability for small hospitals were the main factor preventing surgeons from practicing the best method.

Conclusion: Risk of endophthalmitis can be reduced by following proper drug dispensing techniques. Aliquoting bevacizumab in smaller syringes under aseptic conditions can reduce the risk of endophthalmitis.

Key words: Intravitreal, Endophthalmitis, Questionnaire, Bevacizumab.
\end{abstract}

\section{INTRODUCTION}

Anti VEGFs have become an indispensable tool for management of various retinal vascular diseases. The most commonly used anti VEGFs are bevacizumab, ranibizumab and aflibercept. Although bevacizumab was the first anti VEGF to be used clinically, it is still not FDA approved for intraocular use. Most of the major studies including CATT trials have shown that both bevacizumab and ranibizumab are equally effective in managing retinal vascular entities (Kodjikian et al, 2013; Krebs et al, 2013; Wells et al, 2015; Chakravarthy et al, 2012; Rosenfeld et al, 2005; Martin et al, 2012). It has been seen that off-label use of bevacizumab is more

$\begin{array}{ll}\text { Financial Interest : Nil } & \text { Received : 20.10.2020 } \\ \text { Conflict of Interest : Nil } & \text { Accepted : 12.04.2021 } \\ \text { Corresponding Author } & \\ \text { Dr. Roshija Khanal Rijal } & \\ \text { ASG Eye Hospital, } & \\ \text { Kathmandu, Nepal. } & \\ \text { E-mail: dr.roshija@gmail.com }\end{array}$

Access this article online

Website: www.nepjol.info/index.php/NEPJOPH DOI: https://doi.org/10.3126/nepjoph.v13i2.32408 Copyright $\odot 2021$ Nepal Ophthalmic Society ISSN: 2072-6805, E-ISSN: 2091-0320

This work is licensed under a Creative Commons Attribution-NonCommercial-NoDerivatives 4.0 International License (CC BY-NC-ND). 
common than FDA approved ranibizumab, "cost" being the major driving factor (Dakin et al, 2014; Cohen et al, 2015). In fact, in developing countries like Nepal, bevacizumab is most commonly available and used as an anti VEGF. The safety profile of both the bevacizumab and ranibizumab have been found to be similar in long term studies (Martin et al, 2012; Ahfat et al, 2013). The incidence of post-intravitreal Bevacizumab endophthalmitis is $0.016-0.026 \%$ (Kumar et al, 2017). Commercially, bevacizumab is available as a $4 \mathrm{ml}$ vial, which is then dispensed in smaller doses and used by ophthalmologists. The main technique for dispensing bevacizumab can be divided into four types: (a) single vial, multiple prick, multiple days - the vial is opened, drug is withdrawn with separate pricks for each patient. The vial is then stored in the refrigerator for 1 to 4 weeks and used as \& when required. (b) same vial, multiple prick, same day - many patients are pooled in one day at same time, vial is opened and all patients are injected in one setting; (c) a vial is opened, drug is aliquoted into multiple syringes under aseptic conditions, placed in double ETO packs and stored in refrigerator for use over 1 to 4 weeks; (d) drug is aliquoted in multiple syringes and packed but injected in one day and remaining syringes are discarded.

The main purpose of this survey was to find out what technique for bevacizumab injection is practiced by ophthalmologists in Nepal. We also evaluated which is the best technique ophthalmologists think and what possible hindrances are there in following it.

\section{MATERIALS AND METHODS}

This study design was a non-interventional online multiple choice questionnaire survey. 'Google forms' was used for this purpose. All known retina practitioners in different parts of Nepal were enlisted. A link was generated and sent to all ophthalmologists registered with Nepal Medical Council. Each participant needed to answer four sets of questions as in Table 1.

Table 1: Multiple choice questionnaire.

\begin{tabular}{|c|c|c|}
\hline S. No & Questions & Options \\
\hline 1 & $\begin{array}{l}\text { What method do you practice } \\
\text { for giving bevacizumab } \\
\text { injection? }\end{array}$ & $\begin{array}{l}\text { a. Same vial, multiple prick, multiple days. } \\
\text { b. Same vial, multiple prick, single day. } \\
\text { c. Drug aliquoted, packed and stored for use on multiple days. } \\
\text { d. Drug aliquoted and all aliquots used on same day. }\end{array}$ \\
\hline 2 & $\begin{array}{l}\text { Which method you think } \\
\text { is 'BEST' (to prevent post } \\
\text { injection endophthalmitis)? }\end{array}$ & $\begin{array}{l}\text { a. Same vial, multiple prick, multiple days. } \\
\text { b. Same vial, multiple prick, single day. } \\
\text { c. Drug aliquoted, packed and stored for use on multiple days. } \\
\text { d. Drug aliquoted and all aliquots used on same day. } \\
\text { e. No scientifically proven method. }\end{array}$ \\
\hline
\end{tabular}




\begin{tabular}{|l|l|ll|}
\hline 3 & If you have chosen different & a. & Too expensive. \\
& options for the first two & b. & Cumbersome. \\
& questions, what do you think & c. & Not suitable for small hospitals. \\
& is the main hindrance in & d. & Do not know the exact procedure. \\
& practicing the best method? & e. & Drug allocation and packing on a small scale is difficult. \\
\hline 4 & In case you use the same vial & a. & Upto 1 week. \\
& for multiple days, how long & b. & Upto 2 weeks. \\
& do you store the drug? & c. & Upto 3 weeks. \\
& & d. & Upto 4 weeks. \\
\hline
\end{tabular}

\section{RESULTS}

There were a total of 34 participants in the survey. Most of the participants (58.8\%) said that they followed procedure (a); followed by procedure (b), (d) and (c) in that order (Figure 1). Majority of participants said that (d) is the best method to give intravitreal injections (Figure 2). Cost and unsuitability for small hospitals were the main factor preventing surgeons from practicing the best method (Figure 3). For multiple day use, most retina practitioners preferred to discard the vial after 1 week (Figure 4).
What method you practise for giving avastin injection

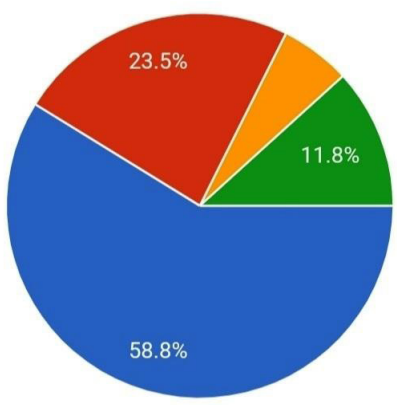

Same vial multiple prick multiple days

Same vial multiple prick single day

Drug aliquoted packed and stored for use on multiple days

Drug aliquoted and all aliquotes used on same $d$.
Which method do you think is 'BEST' (to prevent post injection endophthalmitis)

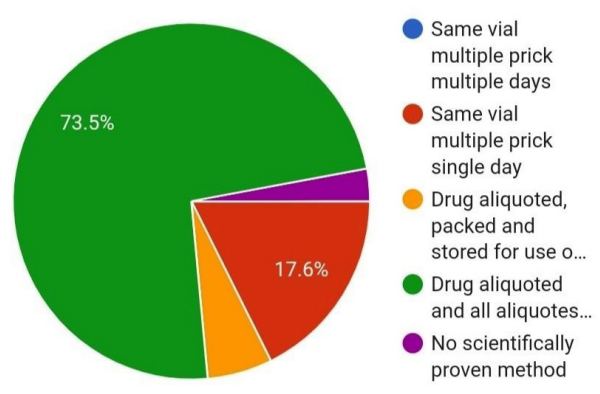

Figure 2 
If you have chosen different options for first two question, what do you think is the main hinderence in practising the 'BEST' method.

The 'BEST' method is

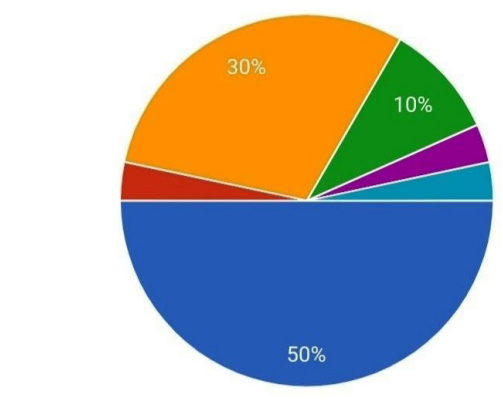

$$
\begin{aligned}
& \text { Too Expensive } \\
& \text { Cumbersome } \\
& \text { Not suitable for } \\
& \text { small hospitals } \\
& \text { Do not know the } \\
& \text { exact procedure } \\
& \text { To develop } \\
& \text { preloaded } \\
& \text { injections of Ava... } \\
& \text { drug allocation } \\
& \text { and packaging in } \\
& \text { small scale is di... }
\end{aligned}
$$

Figure 3

\section{DISCUSSION}

Even though intraocular injection is a safe procedure, it is not devoid of complications. The main complication which ophthalmologists are more concerned with is endophthalmitis. Although incidences of cluster endophthalmitis have been reported more often with bevacizumab, the main cause for this is drug dispensing technique rather than drug compound itself (Omic et al,2014). As bevacizumab is not FDA approved, it is not available for single use. It is available in larger vials available for intravenous use, which are then divided into smaller doses for ophthalmic use. It is this step that is the major concern as a source of infection. Since this is not an FDA approved drug for ophthalmic use, there is no common consensus regarding which is the best technique for drug dispensing. Ophthalmologists follow different drug dispensing techniques based on

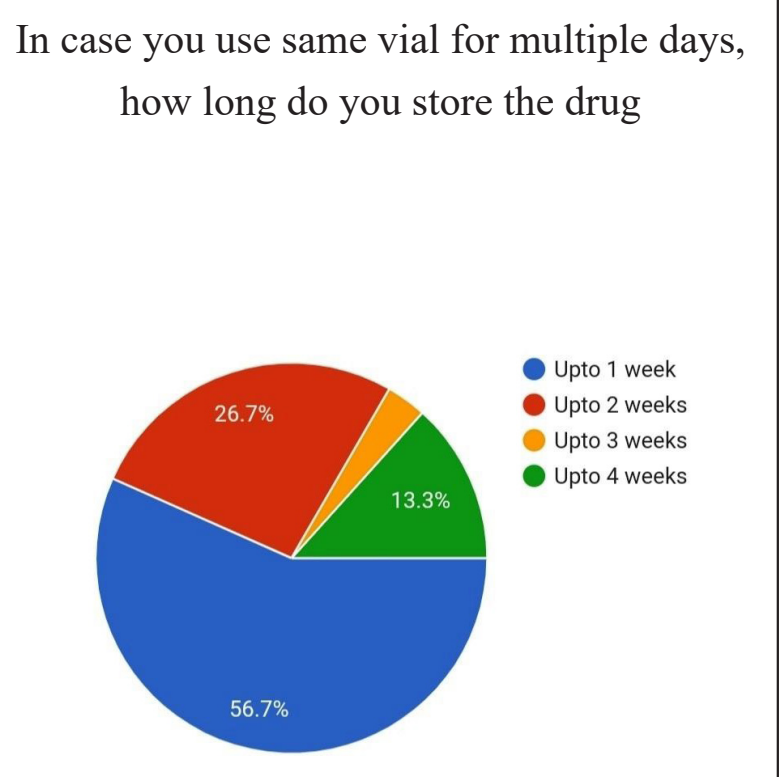

Figure 4

various factors: cost, convenience, availability, patient population, storage facility etc. An ideal technique would be one which is cheap, convenient and has the least risk of infection.

In this survey, procedure (a) was the most commonly followed technique by surgeons in Nepal. This seems to be in accordance with many parts of the world, especially in developing countries. This technique is best suitable for smaller hospitals where there is no ETO facility and where only a few patients need injections on a daily basis. Discarding the vial after single use would not be economical in this setting. The vial is stored in a refrigerator which can have an aseptic environment. Also, there is no clear recommendation as to how long the drug can be stored and its efficacy after opening the vial. Usually, the drug is stored for 4 weeks or even more. $56.7 \%$ of respondents discarded the drug after 1 week, but $13.3 \%$ stored the drug till 4 
weeks. Although maintaining the cold chain and sterility is difficult, most surgeons tend to follow this technique as it is most cost effective.

To prevent the above complications, many surgeons prefer technique (b) wherein the patients are pooled and injected in one setting. The remaining drug is discarded which reduces storage-related complications. In this survey, $23.5 \%$ followed this technique. The main drawback of this technique is that sometimes it may be cumbersome and impractical to call all patients in one day. If the patient misses the day due to any reason, he would have to wait for another schedule which would unnecessarily delay his treatment. Since many patients are injected at one time, if infection occurs, it can turn into large cluster endophthalmitis. Cluster endophthalmitis has been reported after avastin use in many parts of the world. Khan et al,2016, reported an incidence of cluster endophthalmitis in 2016 where six out of eight patients developed endophthalmitis after getting bevacizumab from a single vial. Drugs controller governor of India had temporarily banned bevacizumab use after a similar incident (Kumar et al, 2017).

The third technique (c) is to ETO pack drugs in small syringes and store them. This reduces the risk of multiple punctures. This also reduces the cost as syringes can be stored for a few weeks and less drug is wasted. The All India Ophthalmological Society recommended this technique in their guideline to reduce endophthalmitis risk (Kumar et al, 2017). However, this was the least followed technique $(5.9 \%)$ in this survey. The likely reason here seems to be the unavailability of ETO facilities in many hospitals. $10 \%$ participants also said that there was ambiguity regarding the exact technique of ETO packing under aseptic conditions.

The fourth technique (d) is to aliquot the drug under aseptic conditions and use the syringes on the same day. This reduces the complication of multiple punctures and storage. Only 11.8 $\%$ followed this technique, but $73.5 \%$ of retina practitioners thought that this is the best technique of giving bevacizumab injection. It still has some problems mentioned with technique (b). When asked what were the main hindrances in following the best technique, most said that cost and unsuitability for smaller hospitals were major factors. Other causes were confusion regarding the exact procedure and cumbersome technique.

\section{CONCLUSION}

Bevacizumab is found to be comparable with other anti VEGFs in terms of efficacy and safety profile. But the problem with this drug is lack of guidelines and common consensus in ophthalmic use as this drug lacks FDA approval. Nevertheless, this is definitely the most costeffective anti VEGF in ophthalmic scenario in Nepal. Also, aliquoting bevacizumab in small syringes under aseptic conditions can reduce risk of endophthalmitis. The less the drug is stored the better it is for safety and efficacy issues. Technique (d) can be considered an ideal technique in the present situation. But surgeons can also follow technique (c) which is more economical.

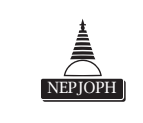




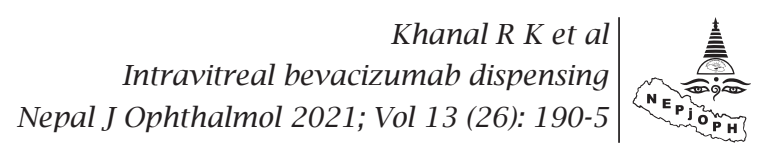

\section{REFERENCES}

Ahfat FG, Zaidi FH. Bevacizumab vs ranibizumab-an appraisal of the evidence from CATT and IVAN. Eye 2013;27:289-90. doi: 10.1038/eye.2013.1; PMid:23485959

Chakravarthy U, Harding SP, Rogers CA, Downes SM, Lotery AJ, et al.; IVAN study investigators. Ranibizumab versus bevacizumab to treat neovascular age- related macular degeneration: One-year findings from the IVAN randomized trial. Ophthalmology 2012;119:1399-411. doi: 10.1016/j.ophtha.2012.04.015; PMid:22578446

Cohen D. Why have UK doctors been deterred from prescribing Avastin? BMJ 2015;350:h1654. doi: 10.1136/bmj. h1654; PMid:25834024

Dakin HA, Wordsworth S, Rogers CA, Abangma G, Raftery J, Harding SP, et al. Cost-effectiveness of ranibizumab and bevacizumab for age-related macular degeneration: 2-year findings from the IVAN randomised trial. BMJ Open 2014;4: e005094. doi: 10.1136/bmjopen-2014-005094; PMid:25079928

Khan P, Khan L, Mondal P. Cluster endophthalmitis following multiple intravitreal bevacizumab injections from a single use vial. Indian J Ophthalmol 2016;64:694-6 doi: 10.4103/0301-4738.99855; PMid:27853027

Krebs I, Schmetterer L, Boltz A, Told R, Vécsei-Marlovits V, Egger S, et al.; MANTA research group. A randomised double-masked trial comparing the visual outcome after treatment with ranibizumab or bevacizumab in patients with neovascular age-related macular degeneration. Br J Ophthalmol 2013;97:266-71. doi: 10.1136/ bjophthalmol-2012-302391; PMid:23292928

Kodjikian L, Souied EH, Mimoun G, Mauget-Faÿsse M, Behar-Cohen F, Decullier E, et al.; GEFAL study group. Ranibizumab versus bevacizumab for neovascular age-related macular degeneration: Results from the GEFAL noninferiority randomized trial. Ophthalmology 2013;120:2300-9. doi: 10.1016/j.ophtha.2013.06.020; PMid:23916488

Kumar A, Ravani R. Using intravitreal bevacizumab (Avastin ${ }^{\circledR}$ ) - Indian Scenario. Indian J Ophthalmol 2017;65:5458. doi: 10.4103/ijo.IJO_431_17; PMid:28724808

Kumar A, Verma L, Aurora A, Saxena R. AIOS-VRSI guidelines for intravitreal injections. Available at http://aios. org/avguidelines.pdf

Martin DF, Maguire MG, Fine SL, Ying GS, Jaffe GJ, Grunwald JE, et al.; Comparison of Age-related Macular Degeneration Treatments Trials (CATT) Research Group. Ranibizumab and bevacizumab for treatment of neovascular age-related macular degeneration. Ophthalmology 2012;119:1388-98. doi: 10.1016/j.ophtha.2012.03.053; PMid:22555112

OMIC and AAO Quality of Care Secretariat, Hoskins Center for Quality Eye Care. Verifying the source of compounded bevacizumab for intravitreal injections-2014. Am Acad Ophthalmol Oct 2014.

Rosenfeld PJ, Fung AE, Puliafito CA. Optical coherence tomography findings after an intravitreal injection of bevacizumab (avastin) for macular edema from central retinal vein occlusion. Ophthalmic Surg Lasers Imaging 2005;36:336-9. doi: 10.3928/1542-8877-20050701-14; PMid:16156153

Wells JA, Glassman AR, Ayala AR, Jampol LM, Aiello LP, Antoszyk AN, et al.; Diabetic Retinopathy Clinical Research Network. Aflibercept, bevacizumab, or ranibizumab for diabetic macular edema. N Engl J Med 2015;372:1193-203. doi: 10.1056/NEJMoa1414264; PMid:25692915 